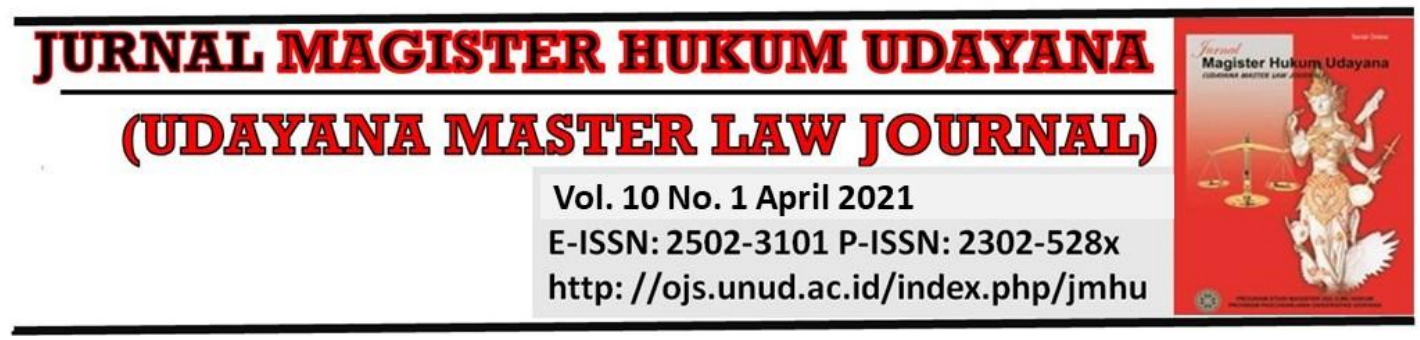

\title{
Perbandingan Penerapan Prinsip Pertanggungjawaban Mutlak Pada Putusan Hakim: Studi Kasus Perkara Lingkungan di Indonesia
}

\author{
I Wayan Dedi Putra1, Kadek Agus Sudiarawan² \\ ${ }^{1}$ Fakultas Hukum Universitas Udayana, E-mail: wyndediputra@gmail.com \\ ${ }^{2}$ Fakultas Hukum Universitas Udayana, E-mail: agus_sudiarawan@unud.ac.id
}

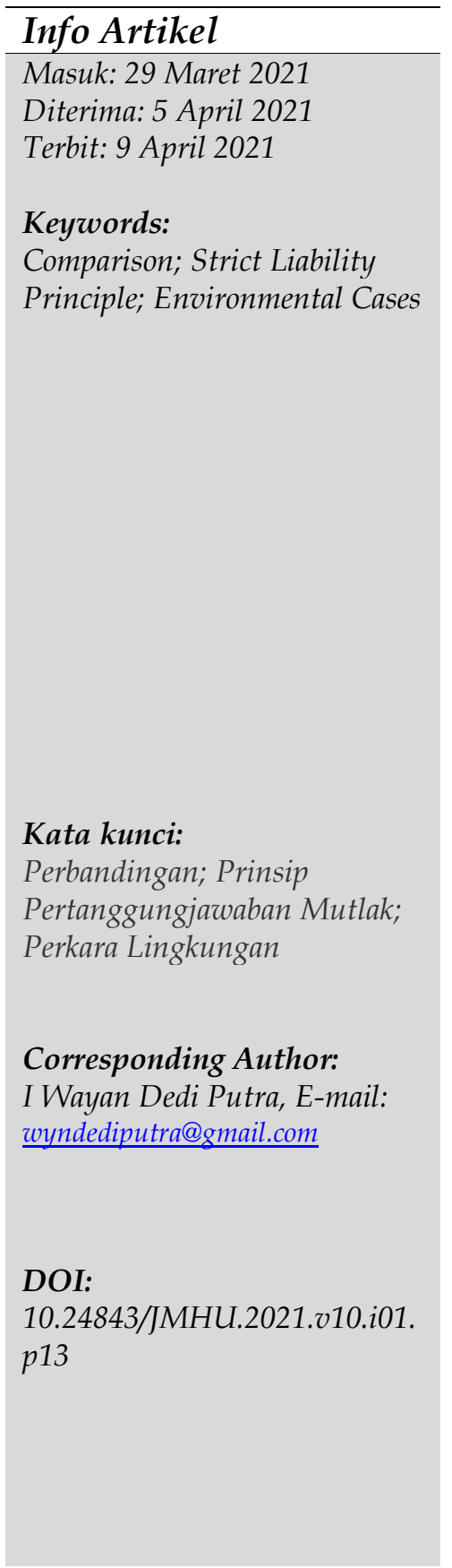

\begin{abstract}
This study aims to examine the application of strict liability principle in $P T W A J ' s$ decision and $P T B M H^{\prime}$ 's decision and also examine the basics of the application of the strict liability principle in environmental cases between PT WAJ's decision and the PT BMH's decision. The research method used is normative legal research. The results of this study are the first, there are a difference in opinion of judges in applying strict liability principle in environmental cases in Indonesia, in PT WAJ's decision, judges applies strict liability principle because it's considered to have fulfilled the elements of Article 88 of the PPLH Law and precautionary principle. Whereas in the PT $B M H^{\prime}$ 's decision, judges put aside the strict liability principle in their legal considerations and didn't provide the reasons. Second, the basics of the application of the strict liability principle in environmental cases between PT WAJ's decision and the PT $B M H^{\prime}$ 's decision, that are the differences in petitum (things requested) from each of the Plaintiffs' lawsuit in the Decision, and judges prioritizes civil procedural law principles in handling act which breaks the law of Environment's cases.
\end{abstract}

\begin{tabular}{l}
\hline Abstrak \\
\hline Penelitian ini bertujuan untuk untuk mengkaji penerapan \\
prinsip pertanggungjawaban mutlak dalam Putusan Nomor \\
$456 / P d t . G-L H / 2016 / P N$ Jkt. Sel (Putusan PT WAJ) dan \\
Putusan Nomor 24/Pdt.G/2015/PN.Plg (Putusan PT BMH) \\
serta mengkaji dasar-dasar yang membedakan diterapkannya \\
prinsip pertanggungjawaban mutlak dalam perkara lingkungan \\
hidup antara Putusan PT WAJ dengan Putusan PT BMH. \\
Metode penelitian yang digunakan yaitu penelitian hukum \\
normatif. Hasil dari penelitian ini, yang pertama adanya \\
perbedaan pendapat majelis hakim dalam penerapan prinsip \\
pertanggungjawaban mutlak dalam perkara lingkungan di \\
Indonesia yaitu dalam Putusan PT WAJ majelis hakim \\
menerapkan prinsip pertanggungjawaban mutlak karena \\
dianggap telah memenuhi unsur-unsur Pasal 88 UU PPLH dan \\
prinsip kehati-hatian, sedangkan dalam Putusan PT BMH, \\
majelis hakim mengesampingkan prinsip pertanggungjawaban \\
mutlak dalam pertimbangan hukumnya dan tidak memberikan \\
alasan atas keputusannya tersebut. Kedua yaitu dasar yang \\
membedakan diterapkannya pertanggungjawaban mutlak dalam \\
perkara lingkungan hidup antara Putusan PT WAJ dengan
\end{tabular}


Putusan PT BMH yaitu adanya perbedaan petitum (hal-hal yang diminta) dari masing-masing Gugatan pihak Penggugat dalam Putusan dan hakim lebih mengedepankan asas-asas hukum acara perdata dalam penanganan perkara PMH Lingkungan.

\section{Pendahuluan}

Masalah dan perkara hukum lingkungan cukup sering terjadi di Indonesia. Padahal dari perspektif hukum, kedudukan dari manusia terhadap lingkungan memiliki arti seharusnya manusia dapat hidup berdampingan dengan sesama dan dengan lingkungannya. ${ }^{1}$ Menurunnya kualitas lingkungan hidup, menunjukan kurangnya perhatian masyarakat terhadap pelestarian lingkungan. ${ }^{2}$ Masalah hukum lingkungan pada dasarnya menyangkut kualitas hidup dari manusia. ${ }^{3}$ Terdapat tiga bentuk masalah lingkungan yaitu pencemaran lingkungan (pollution), pemanfaatan lahan secara salah (land missuse) dan pengurasan atau habisnya sumber daya alam (natural resource depletion). ${ }^{4}$ Berdasarkan Pasal 67 Undang-Undang Nomor 32 Tahun 2009 Tentang Perlindungan dan Pengelolaan Lingkungan Hidup (selanjutnya disebut UU PPLH) menentukan setiap orang berkewajiban memelihara kelestarian fungsi lingkungan hidup serta mengendalikan pencemaran dan/atau kerusakan lingkungan hidup. Pengertian frasa setiap orang dalam UU PPLH tercantum dalam Pasal 1 angka 32 yang menentukan setiap orang adalah orang perseorangan atau badan usaha, baik yang berbadan hukum maupun yang tidak berbadan hukum.

Tanggung jawab tersebut berkaitan dengan perilaku manusia yang berhubungan dengan lingkungan hidup karena sebagian besar penurunan kualitas lingkungan hidup merupakan hasil dari tindakan atau perilaku manusia, ${ }^{5}$ sehingga setiap orang wajib bertanggungjawab terhadap kelestariannya, namun seperti kalimat crime is eternal-as eternal as society yang bermakna di mana ada manusia di sana pasti ada kejahatan, ${ }^{6}$ maka sudah jelas kejahatan lingkungan hidup akan selalu ada dalam

\footnotetext{
${ }^{1}$ Moh. Fadli, Mukhlish, en Mustafa Lutfi, Hukum dan Kebijakan Lingkungan, 1st ed (Malang: UB Press, 2016).h. 10

2 I Gusti Ayu Widiadnyani en Putu Tuni Cakabawa Landra, "Baku Mutu Lingkungan Sebagai Instrumen", Jurnal Magister Hukum Udayana (Udayana Master Law Journal) 9, no 3 (2020): 53546, https://doi.org/10.24843/JMHU.2020.v09.i03.p06. h.536

${ }^{3}$ Siti Sundari Rangkuti, Hukum Lingkungan \& Kebijaksanaan Lingkungan Nasional, 4th ed (Surabaya: Airlangga University Press, 2015). h. 195

${ }^{4}$ Ach. Faisol Triwijaya, Yaris Adhial Fajrin, en Chintya Meilany Nurrahma, "Dual Mediation: Penyelesaian Perkara Lingkungan Hidup yang Melibatkan Korporasi Sebagai Pelaku Melalui Pendekatan Restorative Justice", Jurnal Magister Hukum Udayana 9, no 2 (2020): 401-28, https://doi.org/10.14710/politika.3.2.2012. h.1

${ }^{5}$ Ira Puspita, Linda Ibrahim, en Djoko Hartono, "PENGARUH PERILAKU MASYARAKAT YANG BERMUKIM DI KAWASAN BANTARAN SUNGAI TERHADAP PENURUNAN KUALITAS AIR SUNGAI KARANG ANYAR KOTA TARAKAN (Influence of The Behavior of Citizens Residing in Riverbanks to The Decrease of Water Quality in The River of Karang)", Jurnal Manusia dan Lingkungan 23, no 2 (Julie 2016): 249, https://doi.org/10.22146/jml.18797. h. 250

${ }^{6}$ Iin Ratna Sumirat, "Perlindungan Hukum terhadap Perempuan dan Anak Korban Kejahatan Perdagangan Manusia", Jurnal Studi Gender dan Anak 3, no 1 (2017): 19-30. h.25
} 
kehidupan manusia. Adanya kejahatan tersebut tentunya akan menimbulkan pembentukan dan penegakan hukum sebagaimana asas Ubi Societas Ibi Ius yang bermakna di mana ada masyarakat di situ ada hukum, sehingga kedamaian dan keadilan dari masyarakat hanya bisa dicapai dengan tatanan hukum yang telah terbukti mendatangkan keadilan dan berfungsi secara efektif. ${ }^{7}$

Di Indonesia telah terjadi beberapa perkara lingkungan hidup yang cukup menarik perhatian masyarakat, salah satunya yaitu perkara antara Kementerian Lingkungan Hidup dan Kehutanan Republik Indonesia (KLHK RI) melawan PT Waringin Agro Jaya pada tahun 2016 mengenai ganti rugi yang diminta oleh pemerintah berkaitan dengan kebakaran hutan di Kabupaten Ogan Komering Ilir dan Kabupaten Musi Banyuasin, Provinsi Sumatera Selatan sebagaimana Putusan Nomor 456/Pdt.GLH/2016/PN Jkt. Sel (selanjutnya disebut Putusan PT WAJ) dan perkara antara Menteri Lingkungan Hidup Republik Indonesia melawan PT Bumi Mekar Hijau pada tahun 2015 mengenai ganti rugi yang diminta oleh pemerintah berkaitan dengan kebakaran hutan di lahan milik PT Bumi Mekar Hijau sebagaimana Putusan Nomor 24/Pdt.G/2015/PN.Plg (untuk selanjutnya disebut Putusan PT BMH)

Kedua perkara tersebut sama-sama perkara Gugatan Perbuatan Melawan Hukum $(\mathrm{PMH})$ akan tetapi terdapat perbedaan yang mendasar dalam pertimbangan hakim mengenai penerapan prinsip pertanggungjawaban mutlak (strict liability) oleh majelis hakim yang memeriksa dan mengadili perkara tersebut. Mengenai prinsip pertanggungjawaban mutlak dapat dilihat dalam Pasal 88 UU PPLH yang menentukan bahwa setiap orang yang tindakannya, usahanya, dan/atau kegiatannya menggunakan B3, menghasilkan dan/atau mengelola limbah B3, dan/atau yang menimbulkan ancaman serius terhadap lingkungan hidup bertanggung jawab mutlak atas kerugian yang terjadi tanpa perlu pembuktian unsur kesalahan, sehingga berkaitan ganti kerugian atas perbuatan melawan hukum tidak perlu dibuktikan karena pada dasarnya setiap orang termasuk badan hukum harus bertanggungjawab secara mutlak. Pada dasarnya penegakan hukum lingkungan memang harus dilaksanakan secara efektif, konsekuen dan konsisten khusunya yang berkaitan dengan pencemaran dan kerusakan lingkungan hidup yang sudah terjadi, hal tersebut secara jelas tertera dalam poin 5 Bagian Umum Penjelasan atas UU PPLH dan hal tersebut sejalan dengan diterapkannya prinsip pertanggungjawaban mutlak dalam UU PPLH.

Penerapan prinsip pertanggungjawabn mutlak di Indonesia tidak seluruhnya berjalan sebagaimana yang tercantum dalam UU PPLH, misalnya dalam Putusan PT WAJ, Majelis Hakim mengabulkan gugatan dari Penggugat untuk seluruhnya dan menggunakan prinsip pertanggungjawaban mutlak sehingga Tergugat dihukum membayar ganti kerugian melalui rekening Kas Negara sebesar Rp. 173.468.991.700,(seratus tujuh puluh tiga milyar empat ratus enam puluh delapan juta sembilan ratus sembilan puluh satu ribu tujuh ratus rupiah), akan tetapi dalam Putusan PT BMH majelis hakim mengesampingkan prinsip pertanggungjawaban mutlak sebagaimana yang dimaksud UU PPLH dan dalam putusannya menolak gugatan Penggugat untuk seluruhnya.

\footnotetext{
${ }^{7}$ M. Yasin Al Arif, "Penegakan Hukum dalam Perspektif Hukum Progresif", Undang: Jurnal Hukum 2, no 1 (2019): 169-92, https:/ / doi.org/10.22437/ujh.2.1.169-192. h.171
} 
Perbedaan penerapan prinsip tersebut tentunya akan menimbulkan asumsi-asumsi dan tidak memberikan kepastian hukum mengenai penerapan prinsip pertanggungjawaban mutlak dalam perkara hukum lingkungan di Indonesia. Berdasarkan uraian tersebut maka permasalahan yang akan dikaji dalam penelitian ini yaitu mengenai perbandingan penerapan prinsip pertanggungjawaban mutlak pada putusan hakim melalui studi kasus perkara lingkungan di indonesia (Putusan PT WAJ dan Putusan PT BMH).

Penelitian ini memiliki tujuan untuk mengkaji penerapan prinsip pertanggungjawaban mutlak dalam Putusan Nomor 456/Pdt.G-LH/2016/PN Jkt. Sel (Putusan PT WAJ) dan Putusan Nomor 24/Pdt.G/2015/PN.Plg (Putusan PT BMH). Penelitian ini juga bertujuan untuk mengkaji dasar-dasar yang membedakan diterapkannya prinsip pertanggungjawaban mutlak dalam perkara lingkungan hidup antara Putusan PT WAJ dengan Putusan PT BMH.

Bahwa penelitian terdahulu yang berkaitan dengan prinsip pertanggungjawaban mutlak (strict liability) dalam perkara hukum lingkungan seperti Analisis Hukum Kasus Kebakaran Hutan Oleh PT. Bumi Mekar Hijau Dikaitkan dengan Asas Strict Liability (Studi Kasus Sengketa Perdata Nomor: 24/Pdt.G/2015/PN.Plg) oleh Ida Bagus Nugraha dan Hananto Widodo, ${ }^{8}$ dan Penerapan Prinsip Strict Liability dalam Pertanggungjawaban Korporasi yang Dianggap Bertanggungjawab atas Kebakaran Hutan di Provinsi Riau oleh Eko Ardiansyah Pandiangan. ${ }^{9}$ Penelitian terdahulu tersebut berbeda fokus pembahasan dengan penelitian ini, yang membahas mengenai dasar perbedaan penerapan prinsip pertanggungjawaban mutlak dalam putusan perkara lingkungan, sehingga ditemukan cara berpikir dari majelis hakim selaku aparat penegak hukum dan dapat diketahui cara-cara yang lebih efektif dalam mengajukan gugatan ganti kerugian terhadap perkara lingkungan agar lebih memiliki kepastian hukum untuk diterima dan dikabulkan oleh hakim, maka dari itu originalitas dari penelitian ini dapat dipertanggungjawabkan.

\section{Metode Penelitian}

Penelitian ini menggunakan metode penelitian hukum normatif, metode penelitian hukum normatif pada dasarnya meneliti kaidah-kaidah hukum dan asas-asas hukum dan mencoba menemukan suatu aturan hukum, prinsip hukum, maupun doktrin hukum guna menjawab isu-isu hukum yang diteliti. ${ }^{10}$ Pendekatan yang digunakan dalam penelitian ini yaitu statute approach (pendekatan perundang-undangan), conceptual approach (pendekatan konsep), case approach (pendekatan kasus) dan

\footnotetext{
${ }^{8}$ Ida Bagus Nugraha, "ANALISIS HUKUM KASUS KEBAKARAN HUTAN OLEH PT. BUMI MEKAR HIJAU DIKAITKAN DENGAN ASAS STRICT LIABILITY (Studi Kasus Sengketa Perdata Nomor: 24/Pdt.G/2015/PN.Plg)", NOVUM : JURNAL HUKUM 4, no 3 (Julie 2017): 103-11, https://doi.org/10.2674/NOVUM.V4I3.22860. h.1

${ }^{9}$ Eko Ardiansyah Pandiangan, Erdianto, en Ledy Diana, "PENERAPAN PRINSIP STRICT LIBILITY DALAM PERTANGGUNGJAWABAN KORPORASI YANG DIANGGAP BERTANGGUNGJAWAB ATAS KEBAKARAN HUTAN DI PROVINSI RIAU", Jurnal Online Mahasiswa (JOM) Bidang Ilmu Hukum 3, no 2 (Oktober 2017): 1-14. h.1

${ }^{10}$ Eko Noer Kristiyanto, "Jangkauan Hukum Nasional terhadap Prostitusi Daring", Jurnal Penelitian Hukum De Jure 19, no 1 (2019): 1-10, https:/ / doi.org/10.30641/ dejure.2019.v19.1-10. h. 2
} 
comparative approach (pendekatan perbandingan). Teknik analisis bahan hukum menggunakan teknik Deskriptif Komparatif, yaitu: analisis yang membandingkan 2 (dua) variabel atau status fenomena dengan kata-kata atau kalimat, kemudian dipisahkan menurut kategorinya untuk memperoleh suatu kesimpulan.

Analisis kajian menggunakan analisis kualitatif. Analisis kualitatif artinya menguraikan data dalam bentuk kalimat yang teratur, runtut, logis, tidak tumpang tindih, dan efektif sehingga memudahkan pemahaman interpretasi data. Analisis kualitatif berpedoman pada pendekatan keobjektivisan, sistematis, dan generalisasi.

\section{Hasil dan Pembahasan}

\subsection{Penerapan Prinsip Pertanggungjawaban Mutlak dalam Putusan PT WAJ dan Putusan PT BMH}

\subsubsection{Pengaturan Prinsip Pertanggungjawaban Mutlak dalam UU PPLH}

Pertanggungjawaban hukum dibagi menjadi 3 (tiga) macam, yaitu: (a) pertama, tanggung jawab hukum atas dasar kesalahan (based on fault liability) sebagaimana diatur dalam Pasal 1365 KUH Perdata mengenai kewajiban mengganti kerugian terhadap perbuatan melawan hukum (b) kedua, tanggung jawab hukum berdasarkan praduga bersalah (presumtion of liability); (c) ketiga, tanggung jawab mutlak (absolute liability atau strict liability). ${ }^{11}$ Berkaitan dengan prinsip pertanggungjawaban mutlak dalam perkara lingkungan dapat ditemui dalam Pasal 88 UU PPLH yang menentukan setiap orang yang tindakannya, usahanya, dan/atau kegiatannya menggunakan B3, menghasilkan dan/atau mengelola limbah B3, dan/atau yang menimbulkan ancaman serius terhadap lingkungan hidup bertanggung jawab mutlak atas kerugian yang terjadi tanpa perlu pembuktian unsur kesalahan.

Frasa bertanggung jawab mutlak atau strict liability adalah unsur kesalahan tidak perlu dibuktikan oleh pihak penggugat sebagai dasar pembayaran ganti rugi sebagaimana penjelasan Pasal 88 UU PPLH yang merupakan lex specialis (undangundang yang bersifat khusus) dalam gugatan tentang perbuatan melawan hukum $(\mathrm{PMH})$ pada umumnya. Besarnya nilai ganti rugi yang dapat dibebankan terhadap pencemar atau perusak lingkungan hidup menurut Pasal ini dapat ditetapkan sampai batas tertentu.

Adanya frasa batas tertentu menurut Koesnadi Hardjasoemantri mengakui bahwa Pasal 88 UU PPLH dalam kenyataannya tidak bisa berlaku untuk semua kegiatan, tetapi harus diterapkan selektif, dahulu tertuang dalam Pasal 21 Undang-Undang Nomor 23 Tahun 1997 tentang Pengelolaan Lingkungan Hidup (UU PLH Lama) yang pada pokoknya menentukan dalam beberapa kegiatan yang berkaitan dengan jenis sumber daya tertentu tanggung jawab timbul secara mutlak pada perusak dan atau pencemar pada saat terjadinya perusakan dan atau pencemaran lingkungan hidup tersebut. Unsur kesalahan tidaklah menjadi penting untuk menyatakan si pelaku

\footnotetext{
${ }^{11}$ Sutoyo, "PENGATURAN TANGGUNG JAWAB MUTLAK (STRICT LIABILITY) DALAM HUKUM LINGKUNGAN", Jurnal Ilmiah Pendidikan Pancasila dan Kewarganegaraan 24, no 1 (Junie 2011): 1-66, https:// doi.org/10.17977/JPPKN.V24I1.5486. h. 58
} 
bertanggung jawab dalam prinsip Strict Liability, karena disini berlaku asas "res ipsa loquitur", yaitu: fakta sudah bicara sendiri. ${ }^{12}$

\subsubsection{Penerapan Prinsip Pertanggungjawaban Mutlak dalam Perkara Lingkungan}

Konsep pertanggungjawaban mutlak pertama kali diperkenalkan dalam hukum Indonesia melalui UU PLH Lama. Penerapan prinsip pertanggungjawaban mutlak/strict liability terhadap perkara lingkungan di Indonesia baru terdapat 2 (dua) putusan saja, yaitu Putusan Nomor 49/Pdt.G/2003/PN.BDG atau dikenal dengan Putusan Mandalawangi ${ }^{13}$ dan Putusan Nomor 456/Pdt.G-LH/2016/PN Jkt (Putusan PT WAJ) sedangkan sisanya majelis hakim mengesampingkan prinsip tersebut.

Terlebih dahulu perlu diketahui bahwa Putusan PT WAJ dan Putusan PT BMH merupakan perkara mengenai perbuatan melawan hukum lingkungan yang dalam petitumnya penggugat sama-sama meminta pertanggungjawaban dari perusahaan yang dianggap merusak lingkungan dan telah menimbulkan kerugian sehingga harus membayar ganti kerugian. Selanjutnya untuk melihat pendapat majelis hakim dalam penerapan prinsip pertanggungjawaban mutlak, dapat ditelaah melalui pertimbanganpertimbangan hukum dalam 2 (dua) putusan tersebut sebagai berikut.

Putusan yang pertama yaitu Putusan PT WAJ, dalam pertimbangannya majelis hakim perkara a quo menerapkan prinsip pertanggungjawaban mutlak untuk memeriksa dan mengadili perkara a quo sehingga menetapkan Tergugat (Perusahaan) yang dibebankan beban pembuktian dan menetapkan Tergugat bersalah dan harus mengganti kerugian. Berikut uraian pertimbangan majelis hakim yang pada pokoknya sebagai berikut.

a. Bahwa majelis hakim perkara a quo memberikan pertimbangan untuk menentukan apakah Tergugat dapat dimintai pertanggung jawaban atau tidak terhadap terjadinya kebakaran yang berakibat luas tersebut, majelis menarik ketentuan Pasal 88 UU PPLH dan menentukan prinsip pertanggungjawaban mutlak dalam memutus perkara a quo sehingga beban pembuktian dibebankan kepada Tergugat.

b. Bahwa majelis hakim perkara a quo menguraikan unsur-unsur pertanggungjawaban mutlak/strict liability dengan melihat unsur ancaman serius, yang majelis hakim lihat dari adanya dokumen ANDAL dalam kegiatan usaha Tergugat. Adanya ANDAL mencerminkan kegiatan usaha dari Tergugat memerlukan analisis dampak lingkungan yang diperkirakan membahayakan lingkungan hidup, maka usaha dan/atau kegiatan yang dilakukan oleh Tergugat, telah memenuhi unsur menimbulkan ancaman serius terhadap lingkungan hidup.

c. Bahwa berkaitan dengan pertanggungjawaban mutlak, majelis hakim perkara a quo mengaitkan dengan asas kehati-hatian (precautionary principle) sebagaimana Putusan Mahkamah Agung dalam perkara No.1794 K/Pdt/2004 yang lebih dikenal dengan Putusan Mandalawangi dan majelis hakim berpendapat bahwa Tergugat kurang berhati-hati dalam menghadapi musim kemarau yang berpotensi

\footnotetext{
${ }^{12}$ Y. Sari Murti Widiyastuti, Asas-Asas Pertanggungjawaban Perdata, 1st ed (Yogyakarta: Cahaya Atma Pusaka, 2020).h. 170

${ }^{13}$ Imamulhadi, "Perkembangan Prinsip Strict Liability Dan Precautionary Dalam Penyelesaian Sengketa Lingkungan Hidup Di Pengadilan", Mimbar Hukum - Fakultas Hukum Universitas Gadjah Mada 25, no 3 (2014): 416-32, https://doi.org/10.22146/jmh.16070. h.1
} 
menyebabkan kebakaran lahan, padahal kebakaran yang dihadapi oleh Tergugat sudah sering terjadi.

d. Bahwa majelis hakim memberikan pertimbangan dan menyimpulkan dari uraian pasal mengenai strict liability tersebut tidak perlu lagi dipertentangkan apakah Tergugat telah melakukan kesalahan atau tidak dengan adanya kebakaran lahan diatas lahan yang berada dalam pengelolaannya dalam mengusahakan perkebunan tanaman kelapa sawit.

Majelis hakim dalam Putusan PT BMH memberikan pertimbangan yang berbeda dengan Putusan PT WAJ, yakni:

Majelis hakim perkara a quo dalam pertimbangannya mengesampingkan prinsip pertanggungjawaban mutlak/strict liability dan langsung menelaah unsur-unsur perbuatan melawan hukum melalui ketentuan Pasal 183 Rbg dan Pasal 1865 KUH Perdata, sehingga pembuktian dibebankan terlebih dahulu kepada Penggugat, baru kemudian dibebankan kepada pihak Tergugat. Padahal dalam posita gugatan Penggugat memohon kepada majelis hakim mengacu kepada Putusan Mandalawangi yang mengabulkan gugatan ganti kerugian atas dasar adanya tanggungjawab dari pemilik lahan terhadap kerusakan lingkungan yang terjadi di perkebunannya dan fakta-fakta persidangan terutama dalam proses pembuktian terjadi perseteruan berkaitan dengan konsep strict liability, akan tetapi majelis hakim tetap fokus membahas pembuktian PMH berdasarkan hukum acara perdata dan mengesampingkan prinsip pertanggungjawaban mutlak tersebut.

Berdasarkan hal tersebut terlihat bahwa majelis hakim dalam pertimbangan hukumnya memiliki cara pandang yang berbeda dalam hal penerapan prinsip pertanggungjawaban mutlak dalam perkara hukum lingkungan yang berkaitan dengan perbuatan melawan hukum, padahal sangat terang dan jelas dalam perkara tersebut sama-sama terdapat isu penerapan prinsip pertanggungjawaban mutlak /Strict Liability yang secara konsisten diperdebatkan oleh para pihak dimulai dari gugatan, jawaban atas gugatan hingga proses pembuktian surat, saksi beserta ahli.

\subsection{Dasar yang Membedakan Penerapan Prinsip Pertanggungjawaban Mutlak dalam Perkara Lingkungan Hidup antara Putusan PT WAJ dengan Putusan PT BMH}

Pertanggungjawaban mutlak/strict liability merupakan lex specialis dalam perbuatan melawan hukum lingkungan dalam UU PPLH. Seharusnya berkaitan dengan perbuatan melawan hukum lingkungan beban pembuktiannya dijatuhkan kepada Tergugat, akan tetapi penerapan prinsip pertanggungjawaban mutlak/strict liability belum banyak dipergunakan oleh hakim dalam memutus perkara PMH lingkungan.

Hakim dalam memutuskan suatu perkara harus berdasarkan pada pertimbanganpertimbangan yang dapat diterima semua pihak dan tidak menyimpang dari kaidah- 
kaidah hukum yang berlaku. ${ }^{14}$ Menurut R. Soeparmono terdapat beberapa sumber hukum yang dapat diterapkan oleh hakim seperti peraturan perundang-undangan dan peraturan pelaksanaannya, hukum tidak tertulis (hukum adat), putusan desa, yurisprudensi, ilmu pengetahuan maupun doktrin/ajaran para ahli. Adanya beberapa pilihan sumber hukum yang dapat diterapkan oleh hakim dalam memutus suatu perkara tentunya dapat menimbulkan perbedaan pandangan dalam memutus suatu perkara.

Perbedaan antara Putusan PT WAJ dengan Putusan PT BMH, yaitu:

a. Yang pertama terdapat perbedaan pandangan majelis hakim berkaitan perlu atau tidaknya penerapan pertanggungjawaban mutlak dalam perkara PMH Lingkungan yaitu dalam Putusan PT WAJ diterapkannya prinsip pertanggungjawaban mutlak/stricit liability sedangkan dalam Putusan PT BMH majelis hakim tidak mempertimbangkan perlunya penerapan prinsip pertanggungjawaban mutlak dalam kasus tersebut, padahal dalam proses pembuktian isu penerapan pertanggungjawaban mutlak sangat dibahas dengan perang ahli dan UU PPLH menentukan adanya penerapan prinsip pertanggungjawaban mutlak terhadap kasus pencemaran dan pengerusakan lingkungan.

b. Yang kedua, setelah ditelaah lebih lanjut terdapat perbedaan pada petitum gugatan dari masing-masing putusan, dimana dalam Putusan PT WAJ, petitum gugatannya selain memohon kepada majelis hakim perkara a quo agar menyatakan Tergugat telah melakukan Perbuatan Melawan Hukum tetapi juga memohon agar majelis hakim menyatakan Gugatan tersebut menggunakan pembuktian dengan prinsip strict liability, sedangkan dalam Putusan PT BMH, Penggugat juga memohon kepada majelis hakim perkara a quo agar menyatakan Tergugat telah melakukan Perbuatan Melawan Hukum tetapi tidak memohon tentang pembuktian gugatanyannya harus menggunakan prinsip strict liability seperti Petitum Gugatan dalam Putusan PT WAJ

Dalam hukum acara perdata pada prinsipnya para pihak berhak meminta apapun asalkan berkesesuaian dengan peraturan perundang-undangan yang berlaku, karena dalam hukum acara perdata terdapat asas "Actori Incumbit Probatio" sebagaimana Pasal 163 HIR/283 Rbg dan Pasal 1865 KUH Perdata, apabila salah satu pihak mengemukakan peristiwa atau membantah peristiwa, maka pihak tersebut harus membuktikan peristiwa atau bantahannya dalam persidangan.

Melihat perbedaan pandangan majelis hakim dan isi gugatan dari masing-masing pihak dalam putusan tersebut terlihat majelis hakim mengedapankan asas hukum acara perdata, yaitu: Ultra Petita dalam memutus perkara hukum lingkungan. Ultra petita adalah larangan terhadap hakim yang memutus melebihi apa yang dituntut (petitum), hal tersebut diatur dalam Pasal 178 ayat (2) dan (3) Het Herziene Indonesisch Reglement (HIR) atau dalam Pasal 189 ayat (2) dan (3) RBg. ${ }^{15}$

\footnotetext{
${ }^{14}$ Nur Iftitah Isnantiana, "Legal Reasoning Hakim dalam Pengambilan Putusan Perkara di Pengadilan", ISLAMADINA 18, no 2 (Oktober 2017): 41, https://doi.org/10.30595/islamadina.v18i2.1920. h.44

${ }^{15}$ Ibnu Sina Chandranegara, "ULTRA PETITA DALAM PENGUJIAN UNDANG-UNDANG DAN JALAN MENCAPAI KEADILAN KONSTITUSIONAL", Jurnal Konstitusi 9, no 1 (Mei 2016): 27-48, https://doi.org/10.31078/JK\%X. h.28
} 
Selain itu menurut pendapat ahli Dr. Yanti Fristikawati, S.H., M.Hum dalam Putusan PT BMH menyatakan bahwa : "dalam undang-undang lingkungan kita ini ada strict liability, ada PMH (Perbuatan melawan hukum) itu kan hukum acaranya, dalam prosedur pengajuan gugatan apakah PMH dan Strict Liability yang dimasukkan oleh undang-undang secara tegas harus disebutkan dalam gugatan perdata menurut ahli apakah gugatan itu mengacu pada melakukan perbuatan melawan hukum atau dia nyatakan bahwa perusahaan terus melakukan tanggungjawab dengan menggunakan fasilitas yang dimiliki, karena akan berbeda perbuatan melawan hukum 1365 dengan unsur-unsur kesalahan dan lain-lainnya tidak bisa digabung itukan berbeda."

Selain itu melihat prinsip penegakan hukum lingkungan yang tidak dapat berdiri sendiri sebagaimana menurut Nottie Handhaving Milieurecht yang menyatakan bahwa penegakan hukum lingkungan ialah pengawasan dan penerapan atau ancaman, penggunaan instrumen hukum administratif, kepidanaan atau keperdataan guna mencapai penataan ketentuan hukum dan peraturan yang berlaku umum dan individual. Maka dari itu prinsip pertanggungjawaban mutlak dalam UU PPLH belum dipandang berdiri sendiri oleh hakim-hakim di Indonesia serta penerapannya belum konsisten. Akan tetapi melihat 2 (dua) putusan yang telah dibandingkan tersebut untuk memberikan kepastian hukum bagi para pihak, memang seharusnya dalam posita dan petitum gugatan PMH Lingkungan yang berkaitan dengan ganti kerugian lebih baik mencantumkan permintaan kepada majelis hakim mengenai penerapan prinsip pertanggungjawaban mutlak secara tegas, agar hakim mau tidak mau harus mempertimbangkan apa yang dimohonkan oleh para pihak terutama pihak Penggugat.

Jadi konsep yang diterapkan oleh hakim-hakim di Indonesia berkaitan dengan penerapan prinsip pertanggungjawaban mutlak lebih mengedepankan hukum acara perdata, terutama asas ultra petita, karena pada dasarnya hakim bersifat pasif dalam perkara perdata. Hakim bersifat pasif tidak hanya berarti hakim menunggu (tidak mencari-cari perkara) akan tetapi hakim juga hanya memeriksa, mempertimbangkan dan memutus sesuai dengan tuntuan (Petitum) dari para pihak.

\section{Kesimpulan}

Berdasarkan uraian pembahasan diatas maka dapat ditarik kesimpulan yaitu yang pertama, adanya perbedaan penerapan prinsip pertanggungjawaban mutlak dalam putusan perkara lingkungan yaitu pada Putusan PT WAJ, majelis hakim menerapkan prinsip pertanggungjawaban mutlak dalam pertimbangan hukumnya karena memenuhi unsur-unsur pertanggungjawaban mutlak sebagaimana Pasal 88 UU PPLH dan prinsip kehati-hatian, sedangkan dalam Putusan PT BMH, majelis hakim mengesampingkan prinsip pertanggungjawaban mutlak dalam pertimbangan hukumnya dan tidak memberikan alasan atas keputusannya tersebut, karena dalam posita dan petitum gugatan Putusan PT BMH tidak ada yang memohonkan mengenai harus diterapkannya prinsip pertanggungjawaban mutlak dalam perkara tersebut. Kedua, dasar yang membedakan diterapkannya pertanggungjawaban mutlak dalam perkara lingkungan hidup antara Putusan PT WAJ dengan Putusan PT BMH yaitu adanya perbedaan petitum (hal-hal yang diminta) dari masing-masing Gugatan pihak Penggugat dalam Putusan, sehingga terlihat hakim lebih mengedepankan asas-asas 
hukum acara perdata seperti asas ultra petita, dan asas hakim bersifat pasif dalam penanganan perkara perdata seperti PMH Lingkungan.

Adapun rekomendasi atau saran yang penulis berikan yaitu, sebaiknya dalam pembuatan dan pengajuan gugatan $\mathrm{PMH}$ perkara lingkungan antara posita dan petitium harus mencantumkan permintaan penerapan prinsip pertanggungjawaban mutlak. Cara tersebut berguna untuk membuat majelis hakim yang memeriksa perkara PMH perkara lingkungan harus mempertimbangkan prinsip pertanggungjawaban mutlak tersebut karena telah dimasukan kedalam posita dan petitum, sehingga penegakan hukum lingkungan berkaitan dengan permintaan ganti rugi terhadap pencemaran dan perusakan lingkungan lebih memberikan kepastian hukum.

\section{Daftar Pustaka}

Arif, M. Yasin Al. "Penegakan Hukum dalam Perspektif Hukum Progresif". Undang: Jurnal Hukum 2, no 1 (2019): 169-92. https:/ / doi.org/10.22437/ujh.2.1.169-192.

Chandranegara, Ibnu Sina. "ULTRA PETITA DALAM PENGUJIAN UNDANGUNDANG DAN JALAN MENCAPAI KEADILAN KONSTITUSIONAL". Jurnal Konstitusi 9, no 1 (Mei 2016): 27-48. https:/ / doi.org/10.31078/JK\%X.

Imamulhadi. "Perkembangan Prinsip Strict Liability Dan Precautionary Dalam Penyelesaian Sengketa Lingkungan Hidup Di Pengadilan". Mimbar Hukum Fakultas Hukum Universitas Gadjah Mada 25, no 3 (2014): 416-32. https://doi.org/10.22146/jmh.16070.

Isnantiana, Nur Iftitah. "Legal Reasoning Hakim dalam Pengambilan Putusan Perkara di Pengadilan". ISLAMADINA 18, no 2 (Oktober 2017): 41. https://doi.org/10.30595/islamadina.v18i2.1920.

Kristiyanto, Eko Noer. "Jangkauan Hukum Nasional terhadap Prostitusi Daring". Jurnal Penelitian Hukum De Jure 19, no 1 (2019): 1-10. https://doi.org/10.30641/dejure.2019.v19.1-10.

Moh. Fadli, Mukhlish, en Mustafa Lutfi. Hukum dan Kebijakan Lingkungan. 1st ed. Malang: UB Press, 2016.

Nugraha, Ida Bagus. "ANALISIS HUKUM KASUS KEBAKARAN HUTAN OLEH PT. BUMI MEKAR HIJAU DIKAITKAN DENGAN ASAS STRICT LIABILITY (Studi Kasus Sengketa Perdata Nomor: 24/Pdt.G/2015/PN.Plg)". NOVUM : JURNAL HUKUM 4, no 3 (Julie 2017): $103-11$. https://doi.org/10.2674/NOVUM.V4I3.22860.

Pandiangan, Eko Ardiansyah, Erdianto, en Ledy Diana. “PENERAPAN PRINSIP STRICT LIBILITY DALAM PERTANGGUNGJAWABAN KORPORASI YANG DIANGGAP BERTANGGUNGJAWAB ATAS KEBAKARAN HUTAN DI PROVINSI RIAU". Jurnal Online Mahasiswa (JOM) Bidang Ilmu Hukum 3, no 2 (Oktober 2017): 1-14.

Puspita, Ira, Linda Ibrahim, en Djoko Hartono. "PENGARUH PERILAKU MASYARAKAT YANG BERMUKIM DI KAWASAN BANTARAN SUNGAI TERHADAP PENURUNAN KUALITAS AIR SUNGAI KARANG ANYAR KOTA TARAKAN (Influence of The Behavior of Citizens Residing in Riverbanks to The Decrease of Water Quality in The River of Karang)". Jurnal Manusia dan Lingkungan 23, no 2 (Julie 2016): 249. https:/ / doi.org/10.22146/jml.18797.

Siti Sundari Rangkuti. Hukum Lingkungan \& Kebijaksanaan Lingkungan Nasional. 4th ed. Surabaya: Airlangga University Press, 2015. 
Sumirat, Iin Ratna. "Perlindungan Hukum terhadap Perempuan dan Anak Korban Kejahatan Perdagangan Manusia". Jurnal Studi Gender dan Anak 3, no 1 (2017): 1930.

Sutoyo. "PENGATURAN TANGGUNG JAWAB MUTLAK (STRICT LIABILITY) DALAM HUKUM LINGKUNGAN". Jurnal Ilmiah Pendidikan Pancasila dan Kewarganegaraan 24, no 1 (Junie 2011): 1-66. https:// doi.org/10.17977/JPPKN.V24I1.5486.

Triwijaya, Ach. Faisol, Yaris Adhial Fajrin, en Chintya Meilany Nurrahma. “Dual Mediation: Penyelesaian Perkara Lingkungan Hidup yang Melibatkan Korporasi Sebagai Pelaku Melalui Pendekatan Restorative Justice". Jurnal Magister Hukum Udayana 9, no 2 (2020): 401-28. https:/ / doi.org/10.14710/politika.3.2.2012.

Widiadnyani, I Gusti Ayu, en Putu Tuni Cakabawa Landra. “Baku Mutu Lingkungan Sebagai Instrumen". Jurnal Magister Hukum Udayana (Udayana Master Law Journal) 9, no 3 (2020): 535-46. https:// doi.org/10.24843/JMHU.2020.v09.i03.p06.

Widiyastuti, Y. Sari Murti. Asas-Asas Pertanggungjawaban Perdata. 1st ed. Yogyakarta: Cahaya Atma Pusaka, 2020.

\section{Peraturan Perundang-Undangan}

Undang-Undang Nomor 32 Tahun 2009 Tentang Perlindungan dan Pengelolaan Lingkungan Hidup, Lembaran Negara Republik Indonesia Tahun 2009 Nomor 140, Tambahan Lembaran Negara Republik Indonesia Nomor 5059.

Undang-Undang Nomor 23 Tahun 1997 tentang Pengelolaan Lingkungan Hidup, Lembaran Negara Republik Indonesia Tahun 1997 Nomor 68, Tambahan Lembaran Negara Republik Indonesia Nomor 3699.

Kitab Undang-Undang Hukum Perdata (burgerlijk wetboek voor Indonesie).

Het Herziene Indonesisch Reglement (HIR).

Reglement Tot Regeling Van Het Rechtswezen In De Gewesten Buiten Java En Madura. (RBg). 